\title{
PENGARUH LOAN TO DEPOSIT RATIO TERHADAP RETURN ON ASSET PADA PT BANK DANAMON, TBK PERIODE 2010-2020
}

\author{
${ }^{1}$ Achmad Taufik, ${ }^{2 *}$ Sugiyanto \\ Universitas Pamulang, Tangerang Selatan, Banten, Indonesia \\ $\underline{1 \text { achmadtaufik.hasanuddin@gmail.com, 2*dosen00495@unpam.ac.id }}$
}

\begin{abstract}
Abstrak
Penelitian ini bertujuan untuk mengetahui pengaruh Loan to Deposit Ratio terhadap Return on Asset pada PT. Bank Danamon, Tbk. Metode yang digunakan adalah explanatory research. Teknik analisis menggunakan analisis statistik dengan pengujian regresi, korelasi, determinasi dan uji hipotesis. Hasil penelitian ini variabel Loan to Deposit Ratio diperoleh nilai rata-rata sebesar 83,45\%. Variabel Loan to Deposit Ratio diperoleh nilai rata-rata 2,66\%. Loan to Deposit Ratio berpengaruh positif dan signifikan terhadap Return on Asset dengan nilai persamaan regresi $\mathrm{Y}=-4,907+0,091 \mathrm{X}$, dan nilai koefisien korelasi 0,697 atau memiliki tingkat hubungan yang sangat kuat dengan nilai determinasi 48,6\%. Uji hipotesis diperoleh signifikansi 0,017 <0,05.
\end{abstract}

Kata Kunci: Rasio Pinjaman Terhadap Deposit, Rasio Pinjaman Terhadap Deposit

\section{Abstract}

This study aims to determine the effect of Loan to Deposit Ratio on Return on Assets at PT. Bank Danamon, Tbk. The method used is explanatory research. The analysis technique uses statistical analysis with regression, correlation, determination and hypothesis testing. The results of this study variable Loan to Deposit Ratio obtained an average value of $83.45 \%$. The Loan to Deposit Ratio variable obtained an average value of $2.66 \%$. Loan to Deposit Ratio has a positive and significant effect on Return on Assets with a regression equation value of $Y=-$ $4.907+0.091 X$, and a correlation coefficient value of 0.697 or has a very strong relationship with a determination value of $48.6 \%$. Hypothesis testing obtained a significance of $0.017<0.05$

Keywords: Loan to Deposit Ratio, Loan to Deposit Ratio

\section{PENDAHULUAN}

Bank adalah suatu lembaga yang bergerak dibidang jasa yang menyediakan jasa keuangan bagi seluruh kalangan masyarakat. Fungsi utamanya ialah menghimpun dana dari masyarakat dan menyalurkan dana kepada masyarakat dengan berbagai tujuan atau disebut finansial intermediary. Kepercayaan masyarakat merupakan suatu hal yang sangat penting untuk perusahaan, tak terkecuali bank, karena dengan tingkat kepercayaan masyarakat yang tinggi terhadap suatu bank maka akan membuat masyarakat tertarik untuk menghimpun dana nya ke bank tersebut.

Dalam menganalisis kinerja keuangan perbankan khususnya profitabilitas, dapat dilakukan analisis rasio keuangan seperti Capital Adequacy Ratio (CAR), Loan to
Deposit Ratio (LDR), Non Performing Loan (NPL), Biaya Operasional Pendapatan Operasional (BOPO), Net Interest Margin (NIM), Dana Pihak Ketiga (DPK), Financing to Deposit Ratio (FDR) dan lain sebagainya.

Variabel dependen (Variabel Y) dalam penelitian ini adalah aspek profitabilitas yang diukur dengan ROA. Loan to Deposit Ratios (ROA) merupakan rasio yang menunjukkan hasil atas jumlah aktiva yang digunakan dalam perusahaan (Kasmir, 2014). ROA diukur dari kemampuan perusahaan dalam menghasilkan laba dengan seluruh asetnya (Husnan dan Pudjiastuti, 2006:74). Dengan demikian, Loan to Deposit Ratios merupakan rasio yang menunjukkan hasil dari jumlah asset yang digunakan dalam perusahaan atau suatu ukuran tentang efisiensi manajemen. ROA menunjukkan hasil dari 
seluruh asset yang dikendalikan dengan mengabaikan sumber pendanaan. Biasanya nilai ROA disajikan dalam bentuk persentase.

Tujuan utama operasional bank adalah memperoleh tingkat profitabilitas yang tinggi. Profitabilitas adalah hasil bersih dari sejumlah kebijakan dan keputusan perusahaan (Lukitasari \& Kartika, 2015). Profitabilitas yang digunakan dalam penelitian ini adalah ROA (Loan to Deposit Ratio), karena ROA sangat penting bagi bank untuk mengukur efektivitas perusahaan dalam menghasilkan profit yang berkaitan dengan ketersediaan aset perusahaan. Semakin besar nilai ROA maka semakin besar pula tingkat keuntungan yang dicapai bank tersebut.

Profitabilitas merupakan salah satu faktor untuk menilai baik buruknya kinerja perusahaan. Loan to Deposit Ratios (ROA) merupakan rasio profitabilitas yang digunakan untuk mengukur efektivitas perusahaan di dalam menghasilkan keuntungan dengan memanfaatkan total aktiva yang dimilikinya. Adapun faktorfaktor yang dapat mempengaruhi profitabilitas suatu perusahaan diantaranya Loan to Deposit Ratio (CR), Total Assets Turnover (TATO), Debt To Equity Ratio (DER), Debt Ratio (DR), Pertumbuhan Penjualan dan Ukuran Perusahaan. Di dalam penelitian ini menggunakan LDR sebagai factor - faktor yang mempengaruhi profitabilitas.

Tabel 1. Nilai LRD dan ROA PT. Bank Danamon Tbk Tahun 2010-2020

\begin{tabular}{c|c|c|} 
Tahun & LDR (\%) & ROA (\%) \\
\hline 2010 & 82.85 & 1.75 \\
\hline 2011 & 91.65 & 3.92 \\
\hline 2012 & 85.54 & 1.96 \\
\hline 2013 & 83.13 & 1.77 \\
\hline 2014 & 89.52 & 2.76 \\
\hline 2015 & 73.33 & 1.68 \\
\hline 2016 & 98.55 & 4.45 \\
\hline 2017 & 88.85 & 3.32 \\
\hline 2018 & 80.52 & 4.11 \\
\hline 2019 & 71.56 & 1.25 \\
\hline 2020 & 72.45 & 2.32 \\
\hline Rata-rata & 83.45 & 2.66 \\
\hline
\end{tabular}

Berdasarkan data pada tabel di atas, menunjukkan bahwa pencapaian Loan deposit ratio (LDR) PT. Bank Danamon Tbk Tahun 2010-2020 berluktuasi. pncapaian terendah dicapai pada tahun 2015 yang hanya mencapai sebesar $73,33 \%$ dan pencapaian tertinggi terjadi tahun 2016 yang mampu mencapai $89,52 \%$. Secara rata-rata dicapai $83,45 \%$ per tahunnya.

Sedangkan profitabilitas yang diukur dengan Return on Asset (ROA) menunjukkan bahwa pencapaian tahun 2010-2020 juga berluktuasi. pncapaian terendah dicapai pada tahun 2019 yang hanya mencapai sebesar $1,25 \%$ dan pencapaian tertinggi terjadi tahun 2016 yang mampu mencapai $4,45 \%$. Secara rata-rata dicapai $2,66 \%$ per tahunnya.

Selain fenomena di atas, penelitian ini juga dilatar belakangi oleh adanya research gap dari hasil temuan peneliti-peneliti terdahulu yang meneliti mengenai faktorfaktor yang mempengaruhi Kinerja Keuangan.

Pengukuran Likuiditas dengan menggunakan pengukuran rasio LDR atau Loan to Deposit Ratio yang diteliti oleh Defri (2012) dan Buchory (2014) menyimpulkan bahwa LDR atau Loan to Deposit Ratio berpengaruh signifikan positif terhadap profitabilitas. Sedangkan menurut Hariemufti (2015) menyimpulkan bahwa LDR tidak signifikan berpengaruh terhadap profitabilitas.

Dengan adanya fenomena-fenomena yang terjadi dan juga research gap yang terjadi pada peneliti-peneliti sebelumnya mengenai hasil temuan yang tidak konsisten terhadap faktor-faktor yang mempengaruhi Kinerja Keuangan pada bank. Oleh karena itu atas dasar tersebut, peneliti tertarik untuk melakukan penelitian kembali dan menguji kembali mengenai "Pengaruh Loan to Deposit Ratio (LDR) Terhadap Return on Asset (ROA) Pada PT. Bank Danamon, Tbk Periode 2010-2020".

\section{METODE}

Populasi dalam penelitian ini laporan keuangan PT. Bank Danamon, Tbk selama 11 tahun dengan sampel yang digunakan dengan teknik pengambilan sampling 
dalam penelitian ini adalah samplel jenuh, dimana semua anggota populasi dijadikan sebagai sampel. Dengan demikian sampel dalam penelitian ini laporan keuangan PT. Bank Danamon, Tbk selama 11 tahun. Adapun jenis penelitian yang dipakai adalah asosiatif, dimana tujuannya adalah untuk mengetahui mencari keterhubungan antara variabel independen terhadap variabel dependennya. Dalam menganalisis data digunakan uji validitas, uji reliabilitas, analisis regresi linier sederhana, koefisien korelasi, koefisien determinasi dan uji hipotesis.

\section{HASIL DAN PEMBAHASAN}

\section{Analisis Deskriptif}

Pada pengujian ini digunakan untuk mengetahui skor minimum dan maksimum skor tertinggi, ratting score dan standar deviasi dari masing-masing variabel. Adapun hasilnya sebagai berikut:

Tabel 2. Hasil Analisis Descriptive Statistics

Descriptive Statistics

$\mathrm{N}$ Minimum Maximum Mean Std. Deviation

\begin{tabular}{c|r|r|r|r|r|r}
\hline LDR & 11 & 71.56 & 98.55 & 83.4500 & 8.59917 \\
\hline ROA & 11 & 1.25 & 4.45 & 2.6627 & 1.11866 \\
\hline Valid N (listwise) & 11 & & & & \\
\hline
\end{tabular}

Pencapaian Loan to Deposit Ratio diperoleh nilai minimum sebesar $71,56 \%$ dan nilai maximum $98,55 \%$ dengan ratarata sebesar $83,45 \%$ dengan standar deviasi 8,59\%. Sedangkan Pencapaian nilai Return on Asset diperoleh nilai minimum sebesar $1,25 \%$ dan nilai maximum 4,45\% dengan rata-rata sebesar $2,66 \%$ dengan standar deviasi $1,12 \%$.

\section{Analisis Kuantitatif}

Pada analisis ini dimaksudkan untuk mengetahui pengaruh variabel independen terhadap variabel dependen. Adapun hasil pengujian sebagai berikut:

a. Analisis Regresi Linier Sederhana

Uji regresi ini dimaksudkan untuk mengetahui perubahan variabel dependen jika variabel independen mengalami perubahan. Adapun hasil pengujiannya sebagai berikut:

Tabel 3. Hasil Pengujian Regresi Linier Sederhana

\section{Coefficients ${ }^{\mathrm{a}}$}

\begin{tabular}{|c|c|c|c|c|c|}
\hline \multirow[b]{2}{*}{ Model } & \multicolumn{2}{|c|}{ Unstandardized Coefficients } & \multirow{2}{*}{$\begin{array}{c}\text { Standardized Coefficients } \\
\text { Beta }\end{array}$} & \multirow[b]{2}{*}{$\mathrm{t}$} & \\
\hline & B & Std. Error & & & $\mathrm{Si}$ \\
\hline 1 (Constant) & -4.907 & 2.606 & & -1.883 & \\
\hline LDR & 091 & .031 & 697 & 2.918 & .0 \\
\hline
\end{tabular}

a. Dependent Variable: ROA

Berdasarkan hasil pengujian pada tabel di atas, diperoleh persamaan regresi $Y=-4,907+0,091 X$. Dari persamaan tersebut dijelaskan sebagai berikut:

Berdasarkan hasil pengujian pada tabel di atas, diperoleh persamaan regresi $\mathrm{Y}=10,553+$ 0,365X1 + 0,378X2. Dari persamaan tersebut dijelaskan sebagai berikut:

1) Konstanta sebesar $-4,907$ diartikan jika Loan to Deposit Ratio tidak ada, maka telah terdapat nilai Return on Asset sebesar $-4,907$ point.

2) Koefisien regresi Loan to Deposit Ratio sebesar 0,091, angka ini positif artinya setiap ada peningkatan Loan to Deposit Ratio sebesar 0,091 point maka Return on Asset juga akan mengalami peningkatan sebesar 0,091 point 
b. Analisis Koefisien Korelasi

Analisis koefisien korelasi dimaksudkan untuk mengetahui tingkt kesangat kuatan hubungan dari

Tabel 4. Hasil Pengujian Koefisien Korelasi Loan to Deposit Ratio Terhadap Return on

Asset.

Correlations $^{b}$

\begin{tabular}{|c|c|c|c|}
\hline \multicolumn{4}{|c|}{$\begin{array}{c}\text { Asset. } \\
\text { Correlations }^{\mathbf{b}}\end{array}$} \\
\hline & & LDR & ROA \\
\hline \multirow[t]{2}{*}{ LDR } & Pearson Correlation & 1 & $.697^{*}$ \\
\hline & Sig. (2-tailed) & & .017 \\
\hline \multirow[t]{2}{*}{ ROA } & Pearson Correlation & $.697^{*}$ & 1 \\
\hline & Sig. (2-tailed) & .017 & \\
\hline
\end{tabular}

${ }^{*}$. Correlation is significant at the 0.05 level (2-tailed).

b. Listwise $\mathrm{N}=11$

Berdasarkan hasil pengujian diperoleh nilai korelasi sebesar 0,697 artinya Loan to Deposit Ratio memiliki hubungan yang kuat terhadap Return hubungan yang kuat terhadap Return
on Asset. variabel independen terhadap variabel dependen baik secara parsial maupun simultan. Adapun hasil pengujian sebagai berikut: c. Analisis Koefisien Determinasi

Analisis koefisien determinasi dimaksudkan untuk mengetahui besarnya persentase pengaruh dari variabel independen terhadap variabel dependen. Adapun hasil pengujian sebagai berikut:

Tabel 5. Hasil Pengujian Koefisien Determinasi Loan to Deposit Ratio Terhadap Return on Asset.

Model Summary

\begin{tabular}{|c|c|c|c|c|}
\hline Model & $\mathrm{R}$ & R Square & $\begin{array}{l}\text { Adjusted R } \\
\text { Square }\end{array}$ & $\begin{array}{l}\text { Std. Error of the } \\
\text { Estimate }\end{array}$ \\
\hline 1 & $.697^{a}$ & .486 & .429 & .84525 \\
\hline
\end{tabular}

a. Predictors: (Constant), LDR

Berdasarkan hasil pengujian diperoleh nilai determinasi sebesar 0,486 artinya Loan to Deposit Ratio memiliki kontribusi pengaruh sebesar 48,6\% terhadap Return on Asset, sedangkan sisanya sebesar $51,4 \%$ dipengaruhi faktor lain.

\section{d. Uji Hipotesis}

Pengujian hipotesis dengan uji $t$ digunakan untuk mengetahui hipotesis mana yang diterima.

Rumusan hipotesis: Terdapat pengaruh yang signifikan antara Loan to Deposit Ratio terhadap Return on Asset.

Tabel 6. Hasil Uji Hipotesis Loan to Deposit Ratio Terhadap Return on Asset.

\section{Coefficients ${ }^{a}$}

Unstandardized Coefficients Standardized Coefficients

\begin{tabular}{lr|r|r|r|r} 
Model & B & Std. Error & Beta & \multicolumn{1}{c}{ t } & Sig. \\
\hline 1 (Constant) & -4.907 & 2.606 & & -1.883 & .092 \\
\hline LDR & .091 & .031 & .697 & 2.918 .017 \\
\hline
\end{tabular}

a. Dependent Variable: ROA

Berdasarkan hasil pengujian pada tabel di atas, diperoleh nilai $\mathrm{t}$ hitung $>\mathrm{t}$ tabel atau $(2,918>2,262)$, dengan demikian hipotesis yang diajukan bahwa terdapat pengaruh yang signifikan atara Loan to Deposit
Ratio terhadap Return on Asset diterima. 
PEMBAHASAN HASIL PENELITIAN

1. Kondisi Nilai Loan to Deposit Ratio

Berdasarkan data empiris dan analisis data, variabel Loan to Deposit Ratio diperoleh nilai rata-rata per tahun sebesar $83,45 \%$.

2. Kondisi Nilai Return on Asset

Berdasarkan data empiris dan analisis data, variabel Return on Asset diperoleh nilai rata-rata per tahun sebesar $2,66 \%$.

3. Pengaruh Loan to Deposit Ratio Terhadap Return on Asset

Loan to Deposit Ratio berpengaruh signifikan terhadap Return on Asset dengan persamaan regresi $\mathrm{Y}=-4,907+$ $0,091 X$, nilai korelasi sebesar 0,697 atau memiliki hubungan yang kuat dengan kontribusi pengaruh sebesar 48,6\%, sedangkan sisanya sebesar 51,4\% dipengaruhi faktor lain. Pengujian hipotesis diperoleh nilai $\mathrm{t}$ hitung $>\mathrm{t}$ tabel atau $(2,918>2,262)$. Dengan demikian hipotesis yang diajukan bahwa terdapat berpengaruh signifikan antara Loan to Deposit Ratio terhadap Return on Asset diterima.

\section{KESIMPULAN DAN SARAN}

\section{Kesimpulan}

a. Kondisi variabel Loan to Deposit Ratio berdasar pada periode laporan keuangan 11 tahun diperoleh Loan to Deposit Ratio rata-rata sebesar $83,45 \%$.

b. Kondisi variabel Loan to Deposit Ratio berdasar pada periode laporan keuangan 11 tahun diperoleh Loan to Deposit Ratio rata-rata sebesar $2,66 \%$.

c. Loan to Deposit Ratio berpengaruh signifikan terhadap Return on Asset dengan persamaan regresi $\mathrm{Y}=-4,907$ + 0,091X, nilai korelasi sebesar 0,697 atau kuat dan kontribusi pengaruh sebesar $48,6 \%$ sedangkan sisanya sebesar $51,4 \%$ dipengaruhi faktor lain. Uji hipotesis diperoleh nilai $\mathrm{t}$ hitung $>$ $\mathrm{t}$ tabel atau $(2,918>2,262)$.

\section{Saran}

a. Pihak manajemen bank agar lebih memperhatikan likuiditas dan menjaga keseimbangan modal perusahaan pada bank dan lebih meningkatkan perolehan capitalnya dalam kegiatannya.

b. Tingkat LDR masih belum mencapai standar yang telah ditetapkan oleh perusahaan. Kiranya pihak perbankan perlu mempertimbangkan aspek Biaya Operasional yang dikeluarkan dan meningkatkan kembali Pendapatan yang masuk guna meminimalisir resiko suatu perusahaan perbankan.

c. Bagi peneliti selanjutnya disarankan untuk melakukan penelitian di luar variabel independen yang digunakan dalam penelitian ini ataupun mengkombinasikan salah satu vaiabel dalam penelitian ini dengan vaiabel lain diluar variabel dalam penelitian ini, agar dapat memperoleh hasil yang lebih bervariatif yang dapat menggambarkan hal-hal apa saja yang dapat berpengaruh terhadap Return on Assets.

\section{DAFTAR PUSTAKA}

Agus Harjito \& Martono, (2010) "Manajemen Keuangan" Yogyakarta: Penerbit Ekonisia.

Agus Sartono. (2010). “Manajemen Keuangan Toeri dan Aplikasi", Edisi keempat, Yogyakarta: Penerbit BPFE.

Algifari. (2015). “Analisis Regresi untuk Bisnis dan Ekonomi". Yogyakarta: BPFE.

Arikunto, Suharsimi (2014). "Prosedur Penelitian Suatu Pendekatan Praktek". Jakarta: Rineka Cipta.

Bambang Riyanto, (2011). "Dasar-dasar Pembelanjaan Perusahaan". Edisi ke empat, BPFE Yogyakarta.

Fahmi, Irham (2012), "Pengantar Manajemen Keuangan" Cetakan pertama. Bandung: Penerbit Alfabeta.

Imam Ghozali (2017). "Aplikasi Analisis Multivariate Dengan Program SPSS". 
Edisi Kelima. Semarang: Badan Penerbit Undip.

Istijanto (2014) "Riset Sumber Daya Manusia". Jakarta: PT. Gramedia Pustaka

Kasmir (2010), “Analisis Laporan keuangan", penerbit raja grafindo persada, Jakarta

Kasmir. (2012) "Pengantar Manajemen Keuangan", Edisi Pertama, Cetakan kedua, Jakarta: Prenada Media.

Kharis, Ismu Fadli (2011). "Studi Mengenai Impulse Buying dalam Penjualan Online". Semarang : Skripsi Universitas Diponegoro

Martono dan Agus Harjito, (2011). "Manajemen Keuangan", Jakarta: Penerbit Ekonisia.

Munawir (2010), “Analisis Laporan Keuangan", Edisi Ke Empat, Penerbit Liberty, Yogyakarta.

Najibullah, N., \& Nurjaya, N. (2021). Pengaruh non Performing Financing dan Financing to Deposit Ratio terhadap Pembiayaan pada Bank DKI Syariah. Jurnal Neraca Peradaban, 1(1), 48-55.

Santoso, Singgih (2015). "Menguasai Statistik Multivariat". Jakarta: PT Elex Media Komputindo.

Sartono, "Manajemen Keuangan Aplikasi Dan Teori", Edisi Keempat, BPFE, Yogyakarta, 2008.

Sawir, (2003). “Analisis Kinerja Keuangan dan Perencanaan Keuangan Perusahaan", Cetakan ketiga, Jakarta: Penerbit PT. Gramedia Pustaka Utama.

Sugiyarso, G. dan F. Winarni, “Manajemen Keuangan (Pemahaman Laporan Keuangan, Pengelolaan Aktiva, Kewajiban dan Modal serta Pengukuran

Sugiyono (2017), “Metode Penelitian Administrasi : dilengkapi dengan Metode R \& D". Bandung: Alfabeta. 